\title{
Larvicidal activity of Syzygium aromaticum (L.) Merr and Citrus sinensis (L.) Osbeck essential oils and their antagonistic effects with temephos in resistant populations of Aedes aegypti
}

\author{
Adriana Faraco de Oliveira Araujo ${ }^{1 /+}$, João Tadeu Ribeiro-Paes ${ }^{1}$, Juliana Telles de Deus ${ }^{2}$, \\ Sócrates Cabral de Holanda Cavalcanti ${ }^{3}$, Rogéria de Souza Nunes ${ }^{3}$, \\ Péricles Barreto Alves ${ }^{4}$, Maria de Lourdes da Graça Macoris ${ }^{2}$
}

\footnotetext{
${ }^{1}$ Universidade Estadual Paulista, Faculdade de Ciências e Letras, Departamento de Ciências Biológicas, Assis, SP, Brasil ${ }^{2}$ Superintendência de Controle de Endemias, Marília, SP, Brasil ${ }^{3}$ Universidade Federal de Sergipe, Departamento de Farmácia, São Cristóvão, SE, Brasil ${ }^{4}$ Universidade Federal de Sergipe, Departamento de Química, São Cristóvão, SE, Brasil
}

Environmentally friendly botanical larvicides are commonly considered as an alternative to synthetic larvicides against Aedes aegypti Linn. In addition, mosquito resistance to currently used larvicides has motivated research to find new compounds acting via different mechanisms of action, with the goal of controlling the spread of mosquitos. Essential oils have been widely studied for this purpose. This work aims to evaluate the larvicidal potential of Syzygium aromaticum and Citrus sinensis essential oils, either alone or in combination with temephos, on Ae. aegypti populations having different levels of organophosphate resistance. The $50 \%$ lethal concentration $\left(L C_{50}\right)$ of the essential oils alone and in combination with temephos and the influence of essential oils on vector oviposition were evaluated. The results revealed that essential oils exhibited similar larvicidal activity in resistant populations and susceptible populations. However, S. aromaticum and C. sinensis essential oils in combination with temephos did not decrease resistance profiles. The presence of the evaluated essential oils in oviposition sites significantly decreased the number of eggs compared to sites with tap water. Therefore, the evaluated essential oils are suitable for use in mosquito resistance management, whereas their combinations with temephos are not recommended. Additionally, repellency should be considered during formulation development to avoid mosquito deterrence.

Key words: Syzygium aromaticum - Citrus sinensis - Aedes aegypti - vector control - larvicide - dengue

Dengue is currently considered to be one of the most important arboviroses, accounting for substantial morbidity and mortality worldwide. This virus represents a serious public threat, especially in tropical countries, where the warm temperature and environmental conditions favour the development and proliferation of its disease vector, Aedes aegypti Linn. (Sharp et al. 2014). Furthermore, there is currently no vaccine available that acts against the different virus serotypes. As a result, prevention efforts are restricted to focusing exclusively on mosquito control, and the interventions available for prevention and control actions in combatting the vector are therefore limited (Bisset et al. 2011, Coelho 2012). Control strategies frequently focus on the use of chemical larvicides and insecticides, which are mainly organophosphates, such as temephos, and pyrethroids. Such control actions are integrated with environmental management. However, the frequent use of such products has selected for mosquito populations that are resistant to these chem-

doi: 10.1590/0074-02760160075

Financial support: FAPITEC-SE, CNPq (550116-2010-9-Rede Dengue).

+ Corresponding author: adrifaracofb@yahoo.com.br

Received 26 February 2016

Accepted 24 May 2016 icals (Pocquet et al. 2014). In addition, the environmental impacts of pesticides have been widely studied, as they are responsible for non-target toxicity and water stream contamination (Muhammetoglu et al. 2010).

Resistance is commonly related to the activity of enzymes present in the mosquito biochemical routes of insecticide metabolism. Resistance data from São Paulo state reports that the major pathway for the detoxification of temephos, the larvicide that has been widely used in Brazil for over 30 years, is performed by esterases (Melo-Santos et al. 2010). Given the characteristics of $A e$. aegypti populations that are resistant to temephos and other larvicides, the demand for alternative plant-based products with a different mode of action than that which conferred organophosphate resistance is necessary.

In recent years, numerous investigations have been conducted in the search for active compounds from natural sources, with an emphasis on medicinal and aromatic plant essential oils. These oils are widely known for their larvicidal properties, as well as antiviral, fungicidal, antiparasitic and cosmetic properties (Palazzolo et al. 2013, Mittal et al. 2014). The vast Brazilian biodiversity and the insecticidal potential of several unexplored species may provide alternative novel chemical agents to control culicids, especially Ae. aegypti (Brandão et al. 2013, Novaes et al. 2013). The use of plants-based chemicals as an alternative for vector control is based on their usually low toxicity to animals and aquatic ecosystems, in addition to their biodegradability and environmental safety. In con- 
trast, synthetic insecticides, which can cause resistance, are toxic and pollutants (Corrêa \& Salgado 2011).

Several studies have demonstrated the activity of Syzygium aromaticum (L.) Merr. \& Perry and Citrus sinensis (L.) Osbeck essential oils, as well as their major components, against Ae. aegypti larvae (Cavalcanti et al. 2004, Costa et al. 2005, Barbosa et al. 2012, Murugan et al. 2012, Warikoo et al. 2012, Fayemiwo et al. 2014). In this context, we aimed to further evaluate the larvicidal activity of $S$. aromaticum and $C$. sinensis essential oils on insecticide-resistant Ae. aegypti populations, as well as to assess the combined effects of these essential oils and temephos. Furthermore, the oviposition behaviour of females in the presence of these larvicidal agents was evaluated because repellence is detrimental to larvicidal action.

\section{MATERIALS AND METHODS}

Chemicals and essential oil extraction - Temephos $(97.5 \%)$ and Tween 80 were purchased from SigmaAldrich Chemical Co. (St. Louis, MO, USA). Sodium sulphate was purchased from Synth (Brazil). The C. sinensis fruits and dry clove buds (Maratá ${ }^{\mathrm{TM}}$, Itaporanga D'Ajuda, SE, Brazil) used in this study were acquired from a local market in Aracaju city, Sergipe state, Brazil, in a single lot. C. sinensis peels were dried in a circulating air oven at $40^{\circ} \mathrm{C}$ for three days. The dry materials were separately ground and submitted to hydrodistillation for $3 \mathrm{~h}$ in a Clevenger-type apparatus to yield yellowish oils. The essential oils obtained were separated from the aqueous phase, followed by the addition of sodium sulphate $\left(\mathrm{Na}_{2} \mathrm{SO}_{4}\right)$ to remove water residue, and were then filtered and kept in a freezer until further analysis and activity evaluation.

Analytical conditions - The essential oils obtained by hydrodistillation were analysed by gas chromatography-mass spectrometry (GC-MS) using a Shimadzu QP5050A (Shimadzu Europe, North Rhine-Westphalia, Germany) gas chromatograph equipped with a DB-5 MS fused silica column $(30 \mathrm{~m} \times 0.25 \mathrm{~mm}$; film thickness $0.25 \mu \mathrm{m}$ ), under the following conditions: helium as the carrier gas at $1.0 \mathrm{~mL} / \mathrm{min}$; injector split at $250^{\circ} \mathrm{C}$ (split ratio $1 / 20$ ); detector at $280^{\circ} \mathrm{C}$; column temperature programme of $80^{\circ} \mathrm{C}$ for $1.5 \mathrm{~min}$, increase of $4^{\circ} \mathrm{C}$ per min to $180^{\circ} \mathrm{C}$, then $10^{\circ} \mathrm{C}$ per min to $300^{\circ} \mathrm{C}$, ending with a 10 min isothermal at $300^{\circ} \mathrm{C}$. The mass spectra were taken at $70 \mathrm{eV}$ with a scanning speed of $0.85 \mathrm{scan} / \mathrm{s}$ from 40 to $550 \mathrm{Da}$. Peak identification was made on the basis of comparison of their retention indices relative to an $n$-alkane homologous series obtained by co-injecting the oil sample with a linear hydrocarbon mixture.

Quantitative analysis of the chemical constituents was performed by flame ionization gas chromatography (FID) using a Shimadzu GC-17A (Shimadzu Corporation, Kyoto, Japan) instrument under the following operational conditions: a capillary ZB-5MS column (5\% phenyl-arylene-95\%-dimethylpolysiloxane) fused silica capillary column ( $30 \mathrm{~m} \times 0.25 \mathrm{~mm}$ i.d. $\times 0.25 \mu \mathrm{m}$ film thickness) from Phenomenex (Torrance, CA, USA), under the same conditions reported for the GC-MS. Quantification of each constituent was estimated by area normalisation (\%). The compound concentrations were calculated from the GC peak areas and arranged in the order of GC elution.

Stock solutions - Mixtures of C. sinensis or S. aromaticum essential oils and temephos at ratios of 54:1 and 100:1, respectively, were prepared based on previous $\mathrm{LC}_{50}$ data for both essential oils and temephos separately. Thus, a $1 \mathrm{~L}$ solution containing $55 \mathrm{mg}$ of $C$. sinensis/ temephos or $101 \mathrm{mg}$ of $S$. aromaticum/temephos would contain a concentration approximately equivalent to the $\mathrm{LC}_{50}$ of the essential oil and $1 \mathrm{ppm}$ of temephos.

A 20,000 ppm stock solution was prepared using each essential oil or its mixture with temephos $(20 \mathrm{mg} /$ $\mathrm{mL})$, Tween $80(5 \mathrm{~mL})$, and deionized water $(1 \mathrm{~mL})$. The stock solution was used to make $150 \mathrm{~mL}$ water solutions ranging from 0.1 to $220 \mathrm{ppm}$. Temephos was also separately used to monitor Ae. aegypti susceptibility.

Mosquitoes - The Rockefeller strain of Ae. aegypti was maintained under laboratory conditions at a controlled temperature of $25^{\circ} \mathrm{C} \pm 2^{\circ} \mathrm{C}$ and a relative humidity of 70 $\pm 10 \%$. Insecticide-resistant populations were collected from the following counties: Marília, Araçatuba and Santos, São Paulo state, Brazil. Resistant populations were maintained under the same conditions as the Rockefeller strain but in separate rooms. Populations were selected based on previously evaluate levels of insecticide-detoxificant enzymes ( $\alpha$ - and $\beta$-esterases and glutathioneS-transferase). Additionally, the levels of multi-function oxidase enzyme activity in the Marília population were considered normal, while the Araçatuba and Santos populations presented altered activity (Macoris et al. 2003).

Larvicidal assay - Assays were conducted at the Applied Entomology Laboratory (SUCEN, Marília, São Paulo, Brazil) under a controlled environment and were performed according to the procedure recommended by the World Health Organization (WHO 2005). Concentration ranges were determined using a previously generated concentration-response curve for 20 third-instar larvae. Eight different concentrations and four replicates were used for each essential oil mixture and the control. Twenty late third-instar larvae were exposed to $150 \mathrm{~mL}$ solutions of larvicide in disposable cups. A mortality count was conducted $24 \mathrm{~h}$ after treatment. Each experiment was repeated three times in different days, in such a way that 240 larvae were exposed to each larvicide concentration or controls. The controls were prepared with Tween 80 and water at the highest concentration used in each experiment. The organophosphate temephos, a standard insecticide for larvae control, was used as a positive control. In all cases where mortality of between $5-20 \%$ occurred in the control experiment, the data were corrected using Abbott's formula $(\%$ deaths $=$ [1-(test/control)] x 100) (Abbott 1925). Any experiment with over $20 \%$ mortality in controls was discarded.

Oviposition behaviour - To evaluate whether the presence of essential oils in oviposition sites influence the oviposition behaviour of females, two rearing cages, one for each essential oil, were set with field-collected 
(Marília, São Paulo, Brazil), newly emerged Ae. aegypti (100 females and 50 males). The mosquitoes were fed with $10 \%$ honey in cotton pads. After a three-day long copulation period, the cotton pads were removed. On the fourth day, blood was offered via an artificial membrane blood-feeding apparatus. Honey and blood feeding were then offered every other day until the end of the experiment, which extended for 33 days.

Three days after blood feeding, two sites for oviposition were placed in each rearing cage to monitor possible oviposition preferences. One site consisted of a disposable cup containing tap water, and a second cup contained essential oil. The cups were lined with filter paper as a substrate for oviposition and were covered with black cups to control the availability of light. The essential oil concentrations of $C$. sinensis and $S$. aromaticum were 81.44 and $860 \mathrm{ppm}$, respectively, approximately four times the $\mathrm{LC}_{99}$ for the Rockefeller strain, an arbitrary criterion for the use of larvicides in the field (WHO 2005).

Blood feeding was offered three times a week (Mondays, Wednesdays and Fridays). At these times, the paper filters were removed and allowed to dry, and the larvicidal solutions were replaced. To prevent possible effects of local brightness, which can interfere with the choice of oviposition site, the cups were also repositioned during this procedure. After $24 \mathrm{~h}$, the number of eggs was quantified.

Statistical analysis - Probit analysis was conducted on the mortality data collected after $24 \mathrm{~h}$ of exposure to different concentrations of the testing solutions to establish lethal concentrations $\left(\mathrm{LC}_{50}, \mathrm{LC}_{95}\right.$, and $\left.\mathrm{LC}_{99}\right)$ and $95 \%$ confidence intervals (CI) for the respective essential oils or mixtures using the Polo-PC software suite (LeOra Software 1987). The activity of the essential oils or mixtures were considered to be significantly different when their $95 \%$ CIs failed to overlap. The lethal concentrations were used to calculate the resistance ratio (RR) using Equation 1.

$$
R R=\frac{L C_{50} \text { or } L C_{95} \text { of test strain }}{L C_{50} \text { or } L C_{95} \text { of susceptible strain }} \text { Equation } 1
$$

The concentration-response graphics were created using Graph Pad Prism software version 6.0.

The oviposition index (OI, Equation 2) was used to evaluate the oviposition response of females to different sites of oviposition (Marques et al. 2013). The OI varies between -1 and +1 . Substances attracting or stimulating egg deposition result in a positive OI, while substances repelling or inhibiting egg deposition result in a negative OI.

$$
O I=\frac{N t-N c}{N t+N c} \quad \text { Equation } 2
$$

Where $\mathrm{OI}$ is the oviposition index, $\mathrm{Nt}$ is the average number of eggs in the test solution and $\mathrm{Nc}$ is the average number of eggs in the control solution.

Student's t-test was used to compare the number of oviposited eggs in each oviposition site. Graphs showing the total number of eggs in each oviposition site and the total number of eggs over the course of the experiment were created using Graph Pad Prism software version 6.0.

\section{RESULTS AND DISCUSSION}

The essential oils of $C$. sinensis and $S$. aromaticum were obtained at 9.1-19.0\% yield, respectively. Four compounds were identified in the essential oil of $C$. sinensis, representing $99 \%$ of the essential oil, while five compounds were identified in the essential oil of $S$. aromaticum, representing $100 \%$ of the essential oil. Their retention indices and composition percentages, listed in the order of elution in the ZB-5MS column, are given in Table I.

The major component of $C$. sinensis was identified as limonene, accounting for $91.88 \%$ of the essential oil, and for $S$. aromaticum, the main component was eugenol, accounting for $65.99 \%$ of the essential oil.

The Ae. aegypti larvae susceptibility assays demonstrated that $S$. aromaticum and $C$. sinensis essential oils have larvicidal effects in all tested populations. Because no mortality above $20 \%$ in the control groups was observed, the use of Tween 80 as a surfactant had no effect on mortality; therefore, none of the assays were invalidated. Lethal concentrations and their respective CIs are presented in Table II.

TABLE I

Essential oil compositions of Citrus sinensis and Syzygium aromaticum

\begin{tabular}{lccc}
\hline RI & Compound & C. sinensis $(\%$ FID) & S. aromaticum $(\%$ FID) \\
\hline 998 & Mircene & 1.27 & - \\
1003 & $n$-Octanol & 1.09 & - \\
1028 & Limonene & 91.88 & - \\
1099 & Linalool & 4.76 & 65.99 \\
1354 & Eugenol & - & 28.32 \\
1421 & $\beta$-Caryophyllene & - & 2.34 \\
1455 & $\alpha$-humulene & - & 3.35 \\
1522 & Eugenol acetate & - & 100.00 \\
\hline Total & & 99.00 & \\
\hline
\end{tabular}

FID: flame ionization gas chromatography; RI: relative retention index calculated against $n$-alkanes, applying the Van den Dool equation; \%: compound percentage. 
TABLE II

Lethal concentrations $\left(\mathrm{LC}_{50}, \mathrm{LC}_{95}\right.$, and $\left.\mathrm{LC}_{99}\right)$ and confidence intervals $(\mathrm{CI})$ of essential oils and their combinations with temephos in Aedes aegypti field-collected in Araçatuba, Marília and Santos and the Rockefeller strain

\begin{tabular}{lcccc}
\hline Larvicide & Strain & $\mathrm{LC}_{50}(95 \% \mathrm{CI}) \mathrm{ppm}$ & $\mathrm{LC}_{95}(95 \%$ CI $) \mathrm{ppm}$ & $\mathrm{LC}_{99}$ (95\% CI) ppm \\
\hline Citrus sinensis & Rockefeller & $11.92(11.7$ to 12.2$)$ & $17.40(16.4$ to 18.9$)$ & $20.36(18.8$ to 22.7$)$ \\
& Araçatuba & $15.06(14.7$ to 15.5$)$ & $27.59(26.3$ to 29.1$)$ & $35.45(33.3$ to 38.1$)$ \\
& Marília & $13.70(13.4$ to 14.0$)$ & $21.08(20.4$ to 21.9$)$ & $25.20(24.1$ to 26.6$)$ \\
& Santos & $16.30(15.5$ to 17.1$)$ & $34.18(31.5$ to 37.7$)$ & $46.40(41.7$ to 53$)$ \\
Syzygium aromaticum & Rockefeller & $93.56(90.1$ to 97.0$)$ & $167.85(157.2$ to 182.1$)$ & $213.83(195.6$ to 239.0$)$ \\
& Araçatuba & $92.97(90.0$ to 95.8$)$ & $163.40(156.2$ to 172.0$)$ & $206.40(194.4$ to 221.4$)$ \\
& Marília & $106.90(103.9$ to 109.8$)$ & $174.20(167.7$ to 181.9$)$ & $213.20(202.6$ to 226.3$)$ \\
C. sinensis + temephos & Santos & $95.00(92.2$ to 97.8$)$ & $155.50(148.3$ to 164.4$)$ & $190.70(179.1$ to 205.6$)$ \\
& Rockefeller & $0.33(0.29$ to 0.35$)$ & $0.57(0.53$ to 0.65$)$ & $0.73(0.64$ to 0.88$)$ \\
& Araçatuba & $1.65(1.48$ to 1.81$)$ & $5.13(4.61$ to 5.83$)$ & $8.21(7.08$ to 9.86$)$ \\
S. aromaticum + temephos & Marília & $1.78(1.61$ to 1.95$)$ & $5.48(4.39$ to 7.80$)$ & $8.75(6.43$ to 14.33$)$ \\
& Santos & $1.88(1.65$ to 2.09$)$ & $5.35(4.62$ to 6.56$)$ & $8.25(6.70$ to 11.14$)$ \\
& Rockefeller & $0.72(0.69$ to 0.75$)$ & $1.00(0.94$ to 1.08$)$ & $1.14(1.06$ to 1.26$)$ \\
& Araçatuba & $1.66(1.5$ to 1.8$)$ & $4.39(3.8$ to 5.4$)$ & $6.60(5.36$ to 8.81$)$ \\
Temephos & Marília & $1.87(1.41$ to 2.21$)$ & $5.20(4.21$ to 7.74$)$ & $7.94(10.98$ to 24.13$)$ \\
& Santos & $1.96(1.75$ to 2.14$)$ & $3.96(3.53$ to 4.65$)$ & $5.30(4.54$ to 6.66$)$ \\
& Rockefeller & $0.0035(0.0034$ to 0.0036$)$ & $0.0052(0.0050$ to 0.0054$)$ & $0.0061(0.0058$ to 0.0065$)$ \\
& Araçatuba & $0.0130(0.012$ to 0.013$)$ & $0.0240(0.023$ to 0.026$)$ & $0.0310(0.028$ to 0.034$)$ \\
& Marília & $0.0088(0.0083$ to 0.0092$)$ & $0.0180(0.017$ to 0.019$)$ & $0.02400(0.022$ to 0.027$)$ \\
& Santos & $0.0120(0.011$ to 0.012$)$ & $0.0200(0.0191$ to 0.022$)$ & $0.0260(0.024$ to 0.028$)$
\end{tabular}

95\% CI: ninety-five percent probability confidence interval.

C. sinensis evaluated as a larvicide exhibited significantly different $\mathrm{LC}_{95} \mathrm{~s}$ in different Ae. aegypti populations because no overlap in $95 \%$ confidence intervals was observed for any population. In contrast, the $\mathrm{LC}_{95}$ for $S$. aromaticum exhibited no significant differences between the field-collected populations and the Rockefeller strain, and within the field-collected populations, only the $\mathrm{LC}_{95} \mathrm{~S}$ for the Santos and Marília populations were significantly different. The average CI ranges for $C$. sinensis and $S$. aromaticum were 3.25 and 17.75, respectively, demonstrating a greater variability of the latter because it had verified activity over a larger range of concentrations.

The combinations of essential oils and temephos evaluated in the field-collected populations of $\mathrm{Ae}$. aegypti had a significantly different $\mathrm{LC}_{95}$ compared to that of the Rockefeller strain, exhibiting a resistance profile close to that of temephos alone.

Chaieb et al. (2007) and Simas et al. (2004) found that $\mathrm{LC}_{50}=44.5 \mathrm{ppm}$ for eugenol, the major compound in $S$. aromaticum essential oil, in Ae. aegypti populations. The larvicidal activity of $S$. aromaticum essential oil has been previously reported by several authors. Costa et al. (2005) found that $\mathrm{LC}_{50}=21.4 \mathrm{ppm}$, while Fayemiwo et al. (2014) found $\mathrm{LC}_{50}=92.56$ and Barbosa et al. (2012) obtained values of 62.3 and $77.0 \mathrm{ppm}$ for field-collected and Rockefeller larvae, respectively. The differences in the $\mathrm{LC}_{50}$ values observed in the present and previous studies can be explained as a result the use of different populations, methodologies, and the composition of the essential oils tested.
The $\mathrm{pH}$ of the deionized water was not altered by the addition of essential oils or mixtures, even at the highest concentration used in the study, eliminating the possibility of larvae mortality caused by increased acidity.

According to Mazzari and Georghiou (Mazzarri \& Georghiou 1995), a mosquito strain is considered susceptible when its resistance ratio is less than five, moderately resistant when the resistance ratio is between five and ten, and highly resistant when the resistance ratio is greater than ten. Accordingly, the results of this study show that the resistance levels to the essential oils alone are low and the field-collected strains are susceptible to the composition of the essential oils. However, the resistance ratio for temephos and the essential oil/temephos combinations is considered moderate (Table III). The C. sinensis/temephos combinations exhibited resistance ratios close to ten. Therefore, within the evaluated products, the $C$. sinensis/temephos mixture is less suitable for use as a larvicide to control this vector.

The Brazilian Ae. aegypti insecticide resistance monitoring network (MoReNAa) suggests a substitution of the larvicide when the resistance ratio is equal to or higher than three (Secretaria de Vigilância em Saúde 2006, unpublished data). Therefore, $C$. sinensis and $S$. aromaticum essential oils are potential candidates for use as auxiliary larvicides to control Ae. aegypti strains that are resistant to temephos, while their combinations with temephos are not recommended for use as larvicides. 
TABLE III

Resistance ratios to the larvicidal compositions for resistant strains

\begin{tabular}{|c|c|c|c|c|}
\hline Larvicide & Strain & $\mathrm{RR} \mathrm{LC}_{50}$ & $\mathrm{RR} \mathrm{LC}_{95}$ & $\mathrm{RR} \mathrm{LC}_{99}$ \\
\hline \multirow[t]{3}{*}{ Citrus sinensis } & Araçatuba & 1.3 & 1.6 & 1.7 \\
\hline & Marília & 1.1 & 1.2 & 1.2 \\
\hline & Santos & 1.4 & 2.0 & 2.3 \\
\hline \multirow[t]{3}{*}{ Syzygium aromaticum } & Araçatuba & 1.0 & 1.0 & 1.0 \\
\hline & Marília & 1.1 & 1.0 & 1.0 \\
\hline & Santos & 1.0 & 0.9 & 0.9 \\
\hline \multirow[t]{3}{*}{ Temephos } & Araçatuba & 3.7 & 4.6 & 5.1 \\
\hline & Marília & 2.5 & 3.5 & 3.9 \\
\hline & Santos & 3.4 & 3.8 & 4.3 \\
\hline \multirow[t]{3}{*}{ C. sinensis + temephos } & Araçatuba & 5.0 & 9.0 & 11.2 \\
\hline & Marília & 5.4 & 9.6 & 12.0 \\
\hline & Santos & 5.7 & 9.4 & 11.3 \\
\hline \multirow[t]{3}{*}{ S. aromaticum + temephos } & Araçatuba & 2.3 & 4.4 & 5.8 \\
\hline & Marília & 2.6 & 5.2 & 7.0 \\
\hline & Santos & 2.7 & 4.0 & 4.6 \\
\hline
\end{tabular}

Concentration-response plots were generated based on the methodology proposed by Bliss (1935) and Fisher (1935), which allows for the comparison between different populations and tested products by transforming the sigmoid concentration-response curves to lines by converting the concentration to a logarithmic scale and the percent mortality to a probit scale, which ranges from two-eight. The lines are illustrated in Fig. 1.

The concentration required by $S$. aromaticum to act as a larvicide is approximately 10 times higher than that of $C$. sinensis (Fig. 1, plots 1A-B). However, the mortality response obtained by the former essential oil in all populations is more homogeneous than that of $C$. sinensis. Furthermore, the concentration needed for temephos alone to act as a larvicide is lower than that of the essential oil/temephos combinations (Fig. 1, plots 1C-E).

According to the concept proposed by Brindley and Selim (Brindley \& Selim 1984), synergists are substances that, although used in sublethal concentrations, confer a higher mortality than that of each single agent. The concentration of temephos to achieve the $\mathrm{LC}_{50}$ in the temephos/essential oil mixtures was higher than that of temephos alone for all tested populations. Therefore, the essential oils in combination with temephos exerted an antagonistic effect (Table IV).

The results of the oviposition behaviour assay demonstrated that gravid females oviposited in all available sites. However, the number of eggs in each site was significantly different $(p<0.05)$. The number of eggs at oviposition sites containing essential oils was significantly lower than the sites containing tap water, as described in Table $\mathrm{V}$ and illustrated in Fig. 2.

Marques et al. (2013) reported the oviposition index (OI), ranging from -1 to +1 , to evaluate oviposition-attractant or -repellent substances. A positive OI means that the substance has an attractant activity, while a negative value means the substance has a repellent activity. C. sinensis and S. aromaticum exhibited OIs of -0.2 and -0.93 , respectively. Although C. sinensis exhibited a low repellency profile, the essential oils evaluated here exhibit negative OIs and therefore have repellent effects on Ae. aegypti oviposition. According to Machado and Fernandes $\mathrm{Jr}$ (2011), essential oils are natural, volatile and complex compounds, characterised by a strong odour, which influence the ovipositional behaviour of the gravid female. Repellence is an aggravating influence for larvicides because the vector avoids oviposition in treated containers, favouring non-treated water sources for oviposition. These results should be considered in the development of new formulations because essential oil volatility increases repellency, and therefore low volatile formulations will decrease repellency.

C. sinensis and S. aromaticum exhibit similar larvicidal activities in Ae. aegypti populations with different susceptibility profiles to the organophosphate temephos. Therefore, the evaluated essential oils have the potential to be used in mosquito control as an alternative to overcome Ae aegypti resistance.

The mechanism of action of the essential oil of $S$. aromaticum is most likely different from that of temephos because no significant difference was observed between the larvicidal activity for this essential oil in susceptible Rockefeller and resistant strains. In contrast, C. sinensis essential oil exhibited significantly different larvicidal activities between the evaluated populations, which indicates either cross-resistance to previously used larvicides or close contact to this essential oil, as São Paulo state is the main citrus producer in Brazil.

The combination of the evaluated essential oils and temephos did not display increased toxicity; therefore, no synergistic effect was observed. Additionally, resis- 

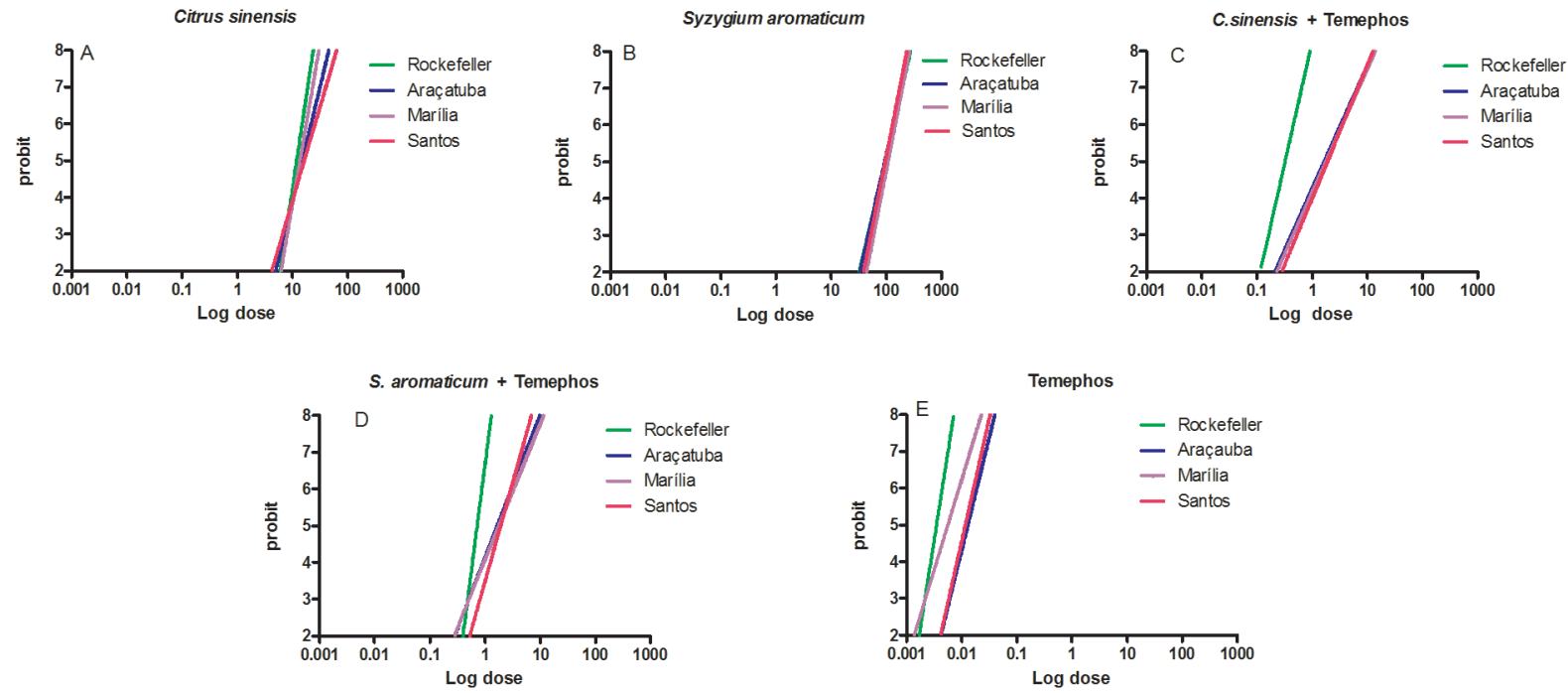

Fig. 1: dose-response curves created using bioassay data after exposure to the essential oils of Citrus sinensis (A) and Syzygium aromaticum (B), temephos combinations (C-D) and temephos alone (E).

TABLE IV

Concentration of temephos at $\mathrm{LC}_{50}$ for the essential oil/temephos combinations and temephos alone

\begin{tabular}{lccc}
\hline Strain & Concentration of temephos $^{1}$ & Concentration of temephos $^{2}$ & Concentration of temephos $^{3}$ \\
\hline Rockefeller & 0.004 & 0.006 & 0.007 \\
Araçatuba & 0.013 & 1.620 & 0.016 \\
Marília & 0.009 & 1.748 & 0.019 \\
Santos & 0.012 & 1.846 & 0.019 \\
\hline
\end{tabular}

${ }^{1}$ alone; ${ }^{2}$ in combination with Citrus sinensis; ${ }^{3}$ in combination with Syzygium aromaticum.

TABLE V

Oviposition response of female Aedes aegypti in oviposition sites containing water, Citrus sinensis, and Syzygium aromaticum essential oils

\begin{tabular}{lcccc}
\hline & S. aromaticum & Water & C. sinensis & Water \\
\hline Total number of eggs per oviposition site & 515 & 14536 & 5050 & 7592 \\
Average number of eggs every $48 \mathrm{~h}$ & 34 & 969 & 337 & 506 \\
Standard deviation & 40.98 & 521.49 & 220.61 & 295,35 \\
Student's t-test & 0.000002 & - & 0.0006 & - \\
Oviposition Index & -0.93 & - & -0.2 & -
\end{tabular}

tance was found to essential oil/temephos combinations, and therefore the combined use of the evaluated essential oils and temephos is not recommended.

The essential oils evaluated here exhibit repellent effects on the oviposition behaviour of Ae. aegypti females. Therefore, volatility should be considered during the development of larvicides formulations containing these products, with the goal of reducing volatility and consequently reducing repellency.

The results suggest that the $S$. aromaticum and $C$. sinensis essential oils represent an alternative as low-toxicity natural larvicides and a promising approach for $A e$. aegypti control, especially in strains showing resistance to currently employed larvicides, such as organophosphates. 

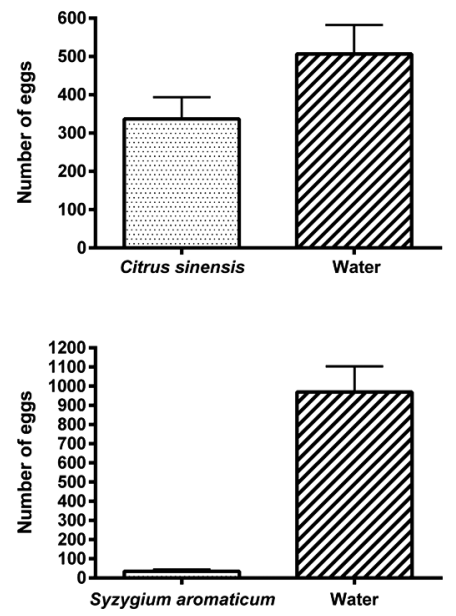

Fig. 2: total number of eggs laid in paired oviposition sites, with and without the presence of each essential oil.

\section{REFERENCES}

Abbott WS. A method of computing the effectiveness of an insecticide. J Econ Entomol. 1925; 18: 265-7.

Barbosa JD, Silva VB, Alves PB, Gumina G, Santos RL, Sousa DP, et al. Structure-activity relationships of eugenol derivatives against Aedes aegypti (Diptera: Culicidae) larvae. Pest Manag Sci. 2012; 68(11): 1478-83.

Bisset JA, Rodríguez MM, Ricardo Y, Ranson H, Perez O, Moya M, et al. Temephos resistance and esterase activity in the mosquito Aedes aegypti in Havana, Cuba increased dramatically between 2006 and 2008. Med Vet Entomol. 2011; 25(3): 233-9.

Bliss CI. The calculation of the dosage-mortality curve. Ann Appl Biol. 1935; 22: 134-67.

Brandão MDL, Cosenza GP, Pereira FL, Vasconcelos AS, Fagg CW. Changes in the trade in native medicinal plants in Brazilian public markets. Environ Monit Assess. 2013; 185(8): 7013-23.

Brindley WA, Selim AA. Synergism and antagonism in the snalysis of insecticide resistance. Environ Entomol. 1984; 13: 348-53.

Cavalcanti ESB, de Morais SM, Lima MAA, Santana EWP. Larvicidal activity of essential oils from Brazilian plants against Aedes aegypti L. Mem Inst Oswaldo Cruz. 2004; 99(5): 541-4.

Chaieb K, Hajlaoui H, Zmantar T, Kahla-Nakbi AB, Rouabhia M, Mahdouani $\mathrm{K}$, et al. The chemical composition and biological activity of clove essential oil, Eugenia caryophyllata (Syzigium aromaticum L. Myrtaceae): a short review. Phytother Res. 2007; 21(6): 501-6.

Coelho GE. Challenges in the control of Aedes aegypti. Rev Inst Med Trop Sao Paulo. 2012; 54(Suppl. 18): S13-4.

Corrêa JCR, Salgado HRN. Insecticidal activities of plants and applications: a review. Rev Bras Plantas Med. 2011; 13(4): 500-6.

Costa JGM, Rodrigues FFG, Angélico EC, Silva MR, Mota ML, Santos NKA, et al. Chemical-biological study of the essential oils of Hyptis martiusii, Lippia sidoides and Syzygium aromaticum against larvae of Aedes aegypti and Culex quinquefasciatus. Rev Bras Farmacogn. 2005; 15(4): 304-9.

Fayemiwo KA, Adeleke MA, Okoro OP, Awojide SH, Awoniyi IO. Larvicidal efficacies and chemical composition of essential oils of Pinus sylvestris and Syzygium aromaticum against mosquitoes. Asian Pac J Trop Biomed. 2014; 4(1): 30-4.

Fisher RA. Appendix to Bliss (1935): the case of zero survivors. Ann Appl Biol. 1935; 22: 164-5.

LeOra Software. POLO-PC: probit or logit analysis. Berkeley: 1987.

Machado BFMT, Fernandes Jr AF. Óleos essenciais: aspectos gerais e usos em terapias naturais. Cad Acad. 2011; 3(2): 105-27.

Macoris MLG, Andrighetti MTM, Takaku L, Glasser CM, Garbeloto VC, Bracco JE. Resistance of Aedes aegypti from the state of São Paulo, Brazil, to organophosphates insecticides. Mem Inst Oswaldo Cruz. 2003; 98(5): 703-8.

Marques GR, Chaves LSM, Serpa LLN, Arduino MB, Chaves FJM. Public drinking water supply and egg laying by Aedes aegypti. Rev Saude Publica. 2013; 47(3): 579-87.

Mazzarri MB, Georghiou GP. Characterization of resistance to organophosphate, carbamate, and pyrethroid insecticides in field populations of Aedes aegypti from Venezuela. J Am Mosq Control Assoc. 1995; 11(3): 315-22.

Melo-Santos MAV, Varjal-Melo JJM, Araujo AP, Gomes TCS, Paiva MHS, Regis LN, et al. Resistance to the organophosphate temephos: mechanisms, evolution and reversion in an Aedes aegypti laboratory strain from Brazil. Acta Trop. 2010; 113(2): 180-9.

Mittal M, Gupta N, Parashar P, Mehra V, Khatri M. Phytochemical evaluation and pharmacological activity of Syzygium aromaticum: a comprehensive review. Int J Pharm Pharm Sci. 2014; 6(8): 67-72.

Muhammetoglu A, Durmaz S, Uslu B. Evaluation of the environmental impact of pesticides by application of three risk indicators. Environ Forensics. 2010; 11(1-2): 179-86.

Murugan K, Kumar PM, Kovendan K, Amerasan D, Subrmaniam J, Hwang JS. Larvicidal, pupicidal, repellent and adulticidal activity of Citrus sinensis orange peel extract against Anopheles stephensi, Aedes aegypti and Culex quinquefasciatus (Diptera: Culicidae). Parasitol Res. 2012; 111(4): 1757-69.

Novaes P, Molinillo JMG, Varela RM, Macias FA. Ecological phytochemistry of Cerrado (Brazilian savanna) plants. Phytochem Rev. 2013; 12(4): 839-55.

Palazzolo E, Laudicina VA, Germana MA. Current and potential use of citrus essential oils. Curr Org Chem. 2013; 17(24): 3042-9.

Pocquet N, Darriet F, Zumbo B, Milesi P, Thiria J, Bernard V, et al. Insecticide resistance in disease vectors from Mayotte: an opportunity for integrated vector management. Parasit Vectors. 2014; 7: 299.

Sharp TM, Mackay AJ, Santiago GA, Hunsperger E, Nilles EJ, PerezPadilla J, et al. Characteristics of a dengue outbreak in a remote pacific island chain - Republic of the Marshall Islands, 20112012. PLoS ONE. 2014; 9(9): e108445.

Simas NK, Lima ED, Conceição SD, Kuster RM, de Oliveira AM, Lage CLS. Natural products for dengue transmission control Larvicidal activity of Myroxylon balsamum (red oil) and of terpencids and phenylpropanoids. Quim Nova. 2004; 27(1): 46-9.

Warikoo R, Ray A, Sandhu JK, Samal R, Wahab N, Kumar S. Larvicidal and irritant activities of hexane leaf extracts of Citrus sinensis against dengue vector Aedes aegypti L. Asian Pac J Trop Biomed. 2012; 2(2): 152-5.

WHO - World Health Organization. Guidelines for laboratory and field testing of mosquito larvicides. 2005. Available from: http://apps.who.int/iris/bitstream/10665/69101/1/WHO_CDS_ WHOPES_GCDPP_2005.13.pdf. 